\title{
Study of the Fastest Rate of Freezing Saline Solution Using Factorial Design Method
}

\author{
Nia Nuraeni Suryaman \\ Department of Mechanical Engineering, Widyatama University, Indonesia
}

Copyright $\odot 2019$ by authors, all rights reserved. Authors agree that this article remains permanently open access under the terms of the Creative Commons Attribution License 4.0 International License

\begin{abstract}
An engineer needed the ability to design an experiment research to be effective and efficient to obtain optimal results. The purpose of this experiment is to determine the fastest rate of freezing saline solution. The research process begins with determining the independent variables as much as possible and determines the three independent variables to be tested. After determine variables, and then create table factorial design to determine the research steps as much as 8 times. Then determine the most influential variables using Yates's algorithm was then tested again using response surface methodology (RSM), but for this study only uses two steps of the three step RSM. So it can be concluded that the lower temperature and salinity the faster the rate of freezing for both type of salt, Krosok and salt.
\end{abstract}

Keywords Rate of Freezing, Saline Solution, Factorial Design

\section{Introduction}

An engineer needed the ability to design an experiment research to be effective and efficient to obtain optimal result. These experiments use factorial design methods to make it easier for researchers to get effective and efficient results.

Factorial design is a method for determining the influence of several independent variables on the response. Basically an experiment is designed to determine one variable in one response. Therefore, factorial design can make it easier to experiment with more than one independent variable. Another use of factorial design is that it can reduce the number of experiments we have to do by studying several factors simultaneously.

The purpose of this experiment is to determine the fastest rate of freezing saline solution. The output to be produce of this study is a graph and the most influential variable as a result. In this study the output will be obtained by using factorial design and least square and response surface methodology.

\section{Literature Study}

\subsection{Factorial Design}

Factorial design is an important method to determine the effects of multiple variables on a response/output. Traditionally, experiments are designed to determine the effect of one variable upon one response/output.

There are advantages by combining the study of multiple variables in the same factorial experiment. Factorial design can reduce the number of experiments one has to perform by studying multiple factors simultaneously. Additionally, it can be used to find both main effects (from each independent factor) and interaction effects (when both factors must be used to explain the outcome).

Factorial design is a useful method to design experiments in both laboratory and industrial settings. Because factorial design can lead to a large number of trials, which can become expensive and time-consuming, factorial design is best used for a small number of variables with few states (1 to 3 ). 


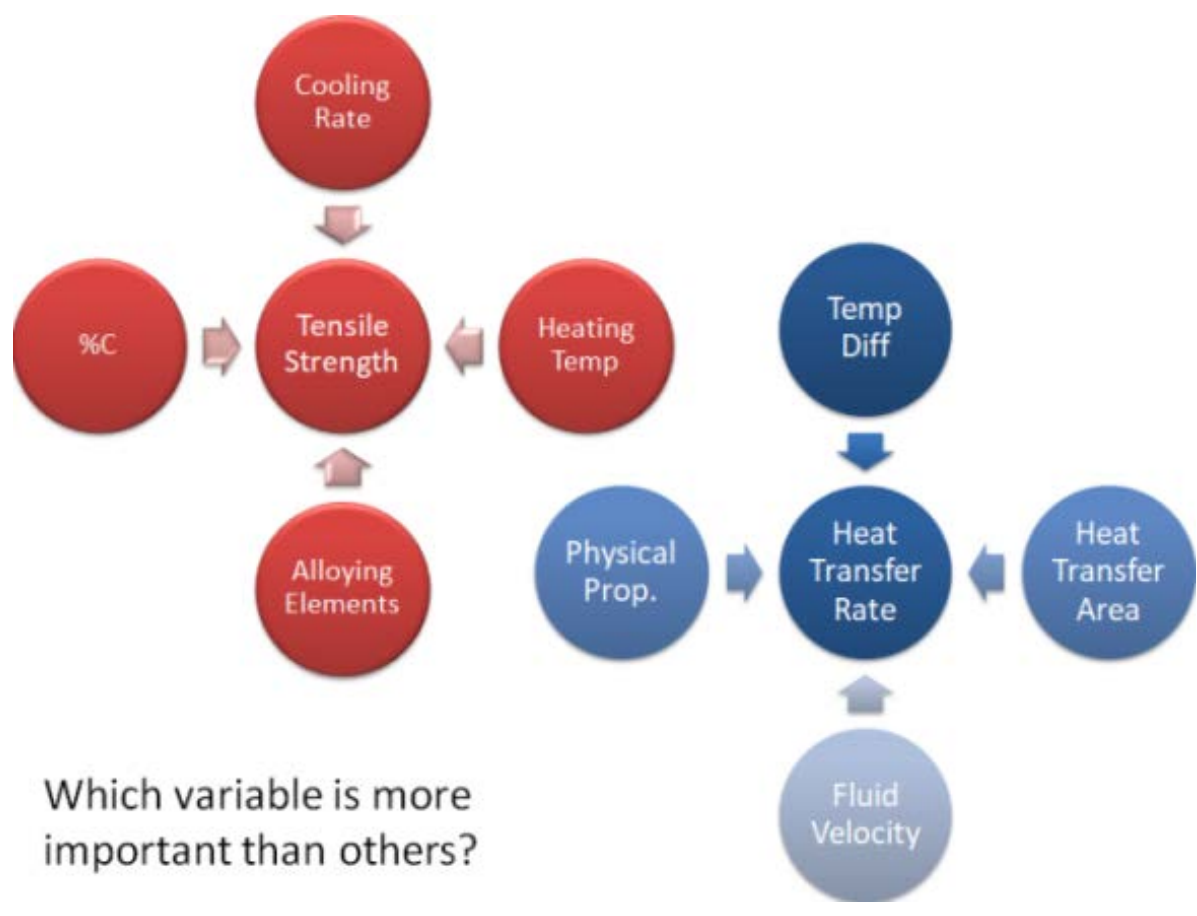

Figure 1. Important Variable

\subsection{Least Square}

The method of least squares is a standard approach to the approximate solution of over determined systems, i.e., sets of equations in which there are more equations than unknowns.

Least square means that the overall solution minimizes the sum of the squares of the errors made in the results of every single equation. The most important application is in data fitting.

In this equation the $\beta$ 's are unknown constants to be estimated and the $\mathrm{x}$ have known values. One common example is where $x_{1}, x_{2}, \ldots$ are the levels of $k$ factors, say temperature $\mathrm{x}_{1}$, line speed $\mathrm{x}_{2}$, concentration $\mathrm{x}_{3}$, and so on, and $\mathrm{y}$ is a measured response such as yield.

$$
y=\beta_{0} x_{0}+\beta_{1} x_{1}+\beta_{2} x_{2}+\ldots+\beta_{k} x_{k}+e
$$

Table 1 shows a small illustrative set of data from an experiment to determine how the initial rate of formation of an undesirable impurity y depended on two factors: $\boldsymbol{A})$ the concentration $x_{o}$ of monomer and $B$ ) the concentration of $\operatorname{dimer} x_{1}$. The mean rate of formation y was zero when both components $\mathrm{x}_{0}$ and $\mathrm{x}_{1}$ were zero. Over the relevant ranges of $\mathrm{x}_{0}$ and $\mathrm{x}_{1}$ the relationship was expected to be approximated by

$$
y=\beta_{0} x_{0}+\beta_{1} x_{1}+e
$$

For any particular set of trial values of the parameters $\beta_{0}$ and $\beta_{1}$ could calculate $\mathrm{S}(\beta)$. For example, for data of Table 1 , if $\beta_{0}=1$ and $\beta_{1}=7$, would get:

$$
S(1,7)=\sum\left(y-1 x_{0}-7 x_{1}\right)^{2}=1.9022
$$

Thus in principle could obtain the minimum value of $S$ by repeated calculation for a grid of trial values. It would eventually be able to construct Figure 2, a 3D plot of the sum of squares surface of $\mathrm{S}(\beta)$ versus $\beta_{0}$ and $\beta_{1}$. The coordinates of the minimum value of this surface are the desired least square estimates

$$
\begin{gathered}
b_{0}=1.21 \quad \text { and } \quad b_{1}=7.12 \\
y=1.21 x_{0}+7.21 x_{1}
\end{gathered}
$$


Table 1. Initial Rate of Impurity Investigation

\begin{tabular}{ccccc}
\hline $\begin{array}{l}\text { Observed } \\
\text { Run } \\
\text { Number }\end{array}$ & $\begin{array}{c}\text { Order in } \\
\text { Which Expcriments } \\
\text { Were Performed }\end{array}$ & $\begin{array}{c}\text { Concentration } \\
\text { of Monomer, } \\
x_{0}\end{array}$ & $\begin{array}{c}\text { Concentration } \\
\text { of Dimmer, } \\
x_{1}\end{array}$ & $\begin{array}{c}\text { Initial Rate of } \\
\text { Formation } \\
\text { of Impurity } y\end{array}$ \\
\hline 1 & 3 & 0.34 & 0.73 & 5.75 \\
2 & 6 & 0.34 & 0.73 & 4.79 \\
3 & 1 & 0.58 & 0.69 & 5.44 \\
4 & 4 & 1.26 & 0.97 & 9.09 \\
5 & 2 & 1.26 & 0.97 & 8.59 \\
6 & 5 & 1.82 & 0.46 & 5.09
\end{tabular}

Quantities needed in subsequent calculations: $\sum x_{0}^{2}=7.0552, \sum x_{1}^{2}=3.6353$,

$\sum x_{0} x_{1}=4.1782, \sum x_{0} y=38.2794 . \sum x_{1} y=30.9388, \sum y^{2}=267.9245$

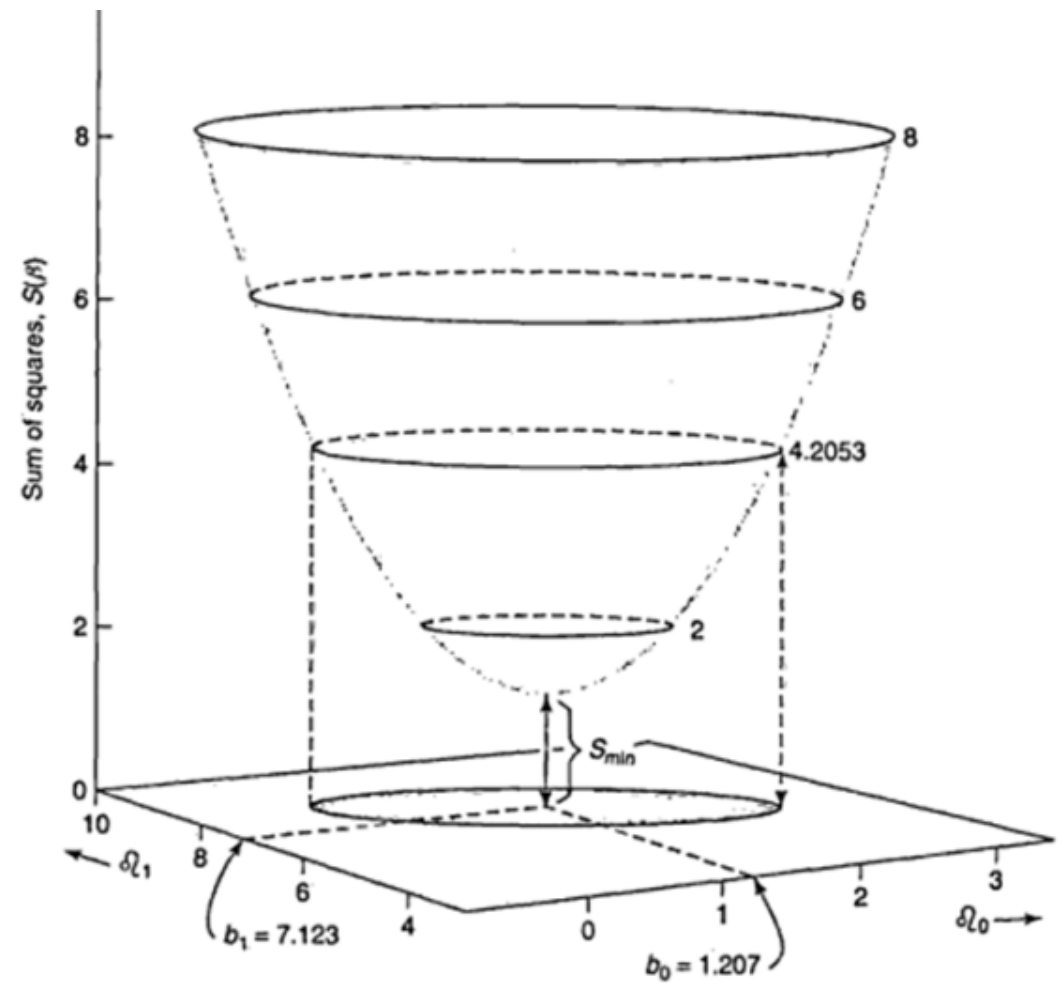

Figure 2. Sum of Square Surface: $S(\beta)=\sum\left(y-\beta_{0} x_{0}-\beta_{1} x_{1}\right)^{2}$

\subsection{Normal Equation}

$$
\begin{aligned}
& \frac{\partial S(\beta)}{\partial \beta_{0}}=-2\left(\Sigma y-\beta_{0} x_{0}-\beta_{0} x_{1}\right) x_{0}=0 \\
& \frac{\partial S(\beta)}{\partial \beta_{1}}=-2\left(\Sigma y-\beta_{0} x_{0}-\beta_{0} x_{1}\right) x_{1}=0
\end{aligned}
$$

After simplification these become what are called the normal equations

$$
\begin{aligned}
& \mathrm{b}_{0} \sum \mathrm{x}_{0}^{2}+\mathrm{b}_{1} \sum \mathrm{x}_{0} \mathrm{x}_{1}=\Sigma \mathrm{yx}_{0} \\
& \mathrm{~b}_{0} \sum \mathrm{x}_{0} \mathrm{x}_{1}+\mathrm{b}_{1} \sum \mathrm{x}_{1}^{2}=\Sigma \mathrm{yx}_{1}
\end{aligned}
$$

\section{Research Methodology}

1) Determined Independent Variable

The independent variables determined for the design of this experiment are as follows:

a) Freezer Temperature

b) Refrigerator

c) Salinity

d) Frozen water mass

e) Freezing time

f) Initial water temperature

g) Type of water

h) Type of salt 
2) After determining the independent variable for the experiment, the next step is to determine the three independent variables to be tested, while the other independent variables are fixed.

a) The independent variables to be tested are:

- $\quad$ Freezer Temperature (Freezer Temperature Setting)

- $\quad$ Freezer temperature settings are varied in:

$>$ Setting 4 , with a temperature of $-17^{\circ} \mathrm{C}$

$>$ Setting 6, with a temperature of $-19^{\circ} \mathrm{C}$

- Salinity

Salinity is varied in:

$>10 \%$ salt

$>\quad 20 \%$ salt

- $\quad$ Type of Salt

Type of salt is varied in:

$>$ Salt

\section{$>$ Krosok}

b) Fixed free variables are:

- Refrigerator Brand

Toshiba

- $\quad$ Frozen Water Mass

250 grams

- $\quad$ Freezing Time

5 hours

- Initial Water Temperature $25^{\circ} \mathrm{C}$

- $\quad$ Type of Water

Tap water

\section{3) Factorial Design Method}

This experiment used the $2^{3}$ factorial design methods with two quantitative factors, temperature and salinity and one qualitative factor, the type of salt.

Table 2. Factorial Design $2^{3}$

\begin{tabular}{|c|c|c|c|}
\hline & Freezer Temperature & Salinity (\%) & Type of Salt \\
\hline+ & $6\left(-19^{\circ} \mathrm{C}\right)$ & 20 & krosok \\
\hline- & $4\left(-17^{\circ} \mathrm{C}\right)$ & 10 & salt \\
\hline
\end{tabular}

Table 3. Factorial Design

\begin{tabular}{|c|c|c|c|c|c|}
\hline Run & Freezer Temperature $\left({ }^{\mathbf{0}} \mathbf{C}\right)$ & Salinity $\mathbf{( \% )}$ & Type of Salt & Ice Mass (g) & Freezing rate (g/jam) \\
\hline 1 & -19 & 20 & krosok & & \\
\hline 2 & -17 & 20 & krosok & & \\
\hline 3 & -19 & 10 & krosok & & \\
\hline 4 & -17 & 10 & krosok & & \\
\hline 5 & -19 & 20 & salt & & \\
\hline 6 & -17 & 20 & salt & & \\
\hline 7 & -19 & 10 & Salt & & \\
\hline 8 & -17 & 10 & Salt & & \\
\hline
\end{tabular}

\section{Results and Discussion}

1) The experiment was carried out in $8 x$ according to the design factorial table that was made before.

Table 4. Experiment Result

\begin{tabular}{|c|c|c|c|c|}
\hline Freezer Temperature $\left({ }^{\circ} \mathbf{C}\right)$ & Salinity (\%) & Type of Salt & Ice Mass (g) & Freezing Rate (g/jam) \\
\hline-19 & 20 & Krosok & 30 & 6 \\
\hline-17 & 20 & Krosok & 0 & 42 \\
\hline-19 & 10 & Krosok & 210 & 30 \\
\hline-17 & 10 & Krosok & 150 & 0 \\
\hline-19 & 20 & Salt & 0 & 0 \\
\hline-17 & 20 & Salt & 0 & 32 \\
\hline-19 & 10 & salt & 160 & 34 \\
\hline-17 & 10 & salt & 170 & 0 \\
\hline
\end{tabular}

2) The Most Influential Variables

The next step after getting the results from the experiment is to determine the most influential variables. Determine the most influential variable using the Yates Algorithm method. 
Table 5. Yates Algorithm

\begin{tabular}{|c|c|c|c|c|c|c|}
\hline \multirow{2}{*}{ Freezing Rate (g/jam) } & \multicolumn{7}{|c|}{ Yates Algorithm } \\
\cline { 2 - 6 } & $\mathbf{1}$ & $\mathbf{2}$ & $\mathbf{3}$ & divider & & explanation \\
\hline 6 & 6 & 78 & 144 & 8 & 18 & average \\
\hline 0 & 72 & 66 & -16 & 4 & -4 & Freezer Temperature \\
\hline 42 & 0 & -18 & 132 & 4 & 33 & Salinity \\
\hline 30 & 66 & 2 & -4 & 4 & -1 & Setting \& Salinity \\
\hline 0 & -6 & 66 & -12 & 4 & -3 & Salinity \\
\hline 0 & -12 & 66 & 20 & 4 & 5 & Type \& Temperature \\
\hline 32 & 0 & -6 & 0 & 4 & 0 & Type \& Salinity \\
\hline 34 & 2 & 2 & 8 & 4 & 2 & Type, Temperature \& Salinity \\
\hline
\end{tabular}

Yates algorithms table above shows that the most influential variable is the salinity.

3) Result of Least Square Method

Table 6. Least Square

\begin{tabular}{|c|c|c|c|c|c|c|c|}
\hline $\begin{array}{c}\text { Freezer Temperature } \\
\left({ }^{\mathbf{}} \mathbf{C}\right)\end{array}$ & Salinity (\%) & $\begin{array}{c}\text { Freezing Rate } \\
\text { (gr/jam) }\end{array}$ & \multicolumn{4}{|l|}{} \\
\hline $\mathbf{T}$ & $\mathbf{S}$ & $\mathbf{F R}$ & $\mathbf{T}^{2}$ & T.S & FR.T & $\mathbf{S}^{2}$ & FR.S \\
\hline-19 & 20 & 6 & 361 & -380 & -114 & 400 & 120 \\
\hline-17 & 20 & 0 & 289 & -340 & 0 & 400 & 0 \\
\hline-19 & 10 & 42 & 361 & -190 & -798 & 100 & 420 \\
\hline-17 & 10 & 30 & 289 & -170 & -510 & 100 & 300 \\
\hline-19 & 20 & 0 & 361 & -380 & 0 & 400 & 0 \\
\hline-17 & 20 & 0 & 289 & -340 & 0 & 400 & 0 \\
\hline-19 & 10 & 32 & 361 & -190 & -608 & 100 & 320 \\
\hline-17 & 10 & 34 & 289 & -170 & -578 & 100 & 340 \\
\hline & $\sum$ & & 2600 & -2160 & -2608 & 2000 & 1500 \\
\hline
\end{tabular}

Normal Equation:

$$
\begin{aligned}
& \mathrm{b} 0 \sum \mathrm{T}^{2}+\mathrm{b} 1 \sum \mathrm{TS}=\mathrm{FRT} \\
& \mathrm{b} 0 \sum \mathrm{TS}+\mathrm{b} 1 \sum \mathrm{S}^{2}=\mathrm{FRS}
\end{aligned}
$$

From the least square table, the normal equation becomes:

$$
\begin{aligned}
& 2600 \text { b0 }-2160 \text { b1 }=-2608 \\
& -2160 b 0+2000 b 1=1500
\end{aligned}
$$

To find the value of b0 and b1 use the Matrix, so that it is obtained:

b0 $=-3.6976$

b1 $=-3.24341$

So the equation obtained is:

$\mathrm{FR}=-3.697 \mathrm{~T}-3.243 \mathrm{~S}$

4) Response Surface Methodology (RSM)

a) Krosok

The first step is to use the initial first order method. This step takes 7 times experiments.

Table 7. Krosok Initial First Order Results

\begin{tabular}{|c|c|c|c|c|}
\hline No & Salinity (\%) & Temperature ( C) & Ice Mass (gram) & Freezing Rate (g/hour) \\
\hline 1 & 20 & -19 & 30 & 6 \\
\hline 2 & 20 & -17 & 0 & 0 \\
\hline 3 & 10 & -19 & 210 & 42 \\
\hline 4 & 10 & -17 & 150 & 30 \\
\hline 5 & 15 & -18 & 80 & 16 \\
\hline 6 & 15 & -18 & 90 & 18 \\
\hline 7 & 15 & -18 & 90 & 18 \\
\hline
\end{tabular}


Determination of angles used using calculations:

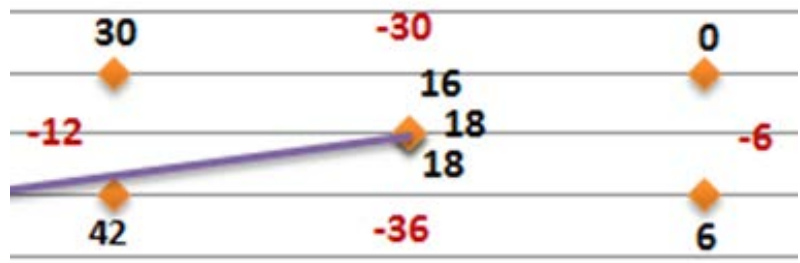

Figure 3. Krosok Angle

$$
\begin{gathered}
\Delta X=\frac{-36+(-30)}{2}=-33 \\
\Delta Y=\frac{-12+(-6)}{2}=-9 \\
\alpha=\operatorname{tg} \frac{\Delta Y}{\Delta X} \\
=\operatorname{tg} \frac{-9}{-33}=15.255
\end{gathered}
$$

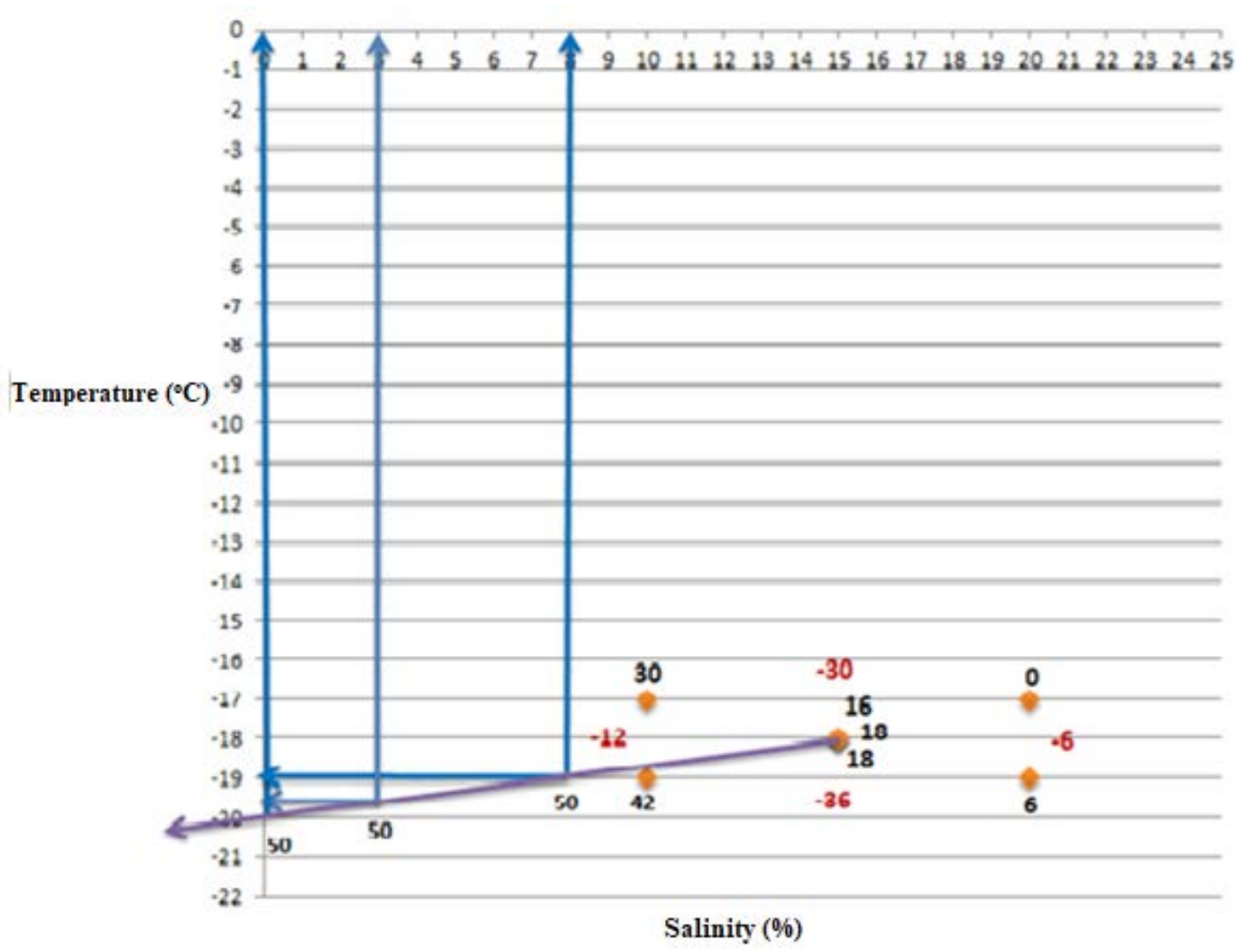

Figure 4. Graph of Experimental Results in Krosok

b) Salt

The step of this type of salt is same with Krosok. The first step is to use the initial first order method. This step takes 7 times experiments. 
Table 8. Salt Initial First Order Result

\begin{tabular}{|c|c|c|c|c|}
\hline No & Salinity (\%) & Temperature ( C) & Ice Mass (gram) & Freezing Rate (g/hour) \\
\hline 1 & 20 & -19 & 0 & 0 \\
\hline 2 & 20 & -17 & 0 & 32 \\
\hline 3 & 10 & -19 & 160 & 34 \\
\hline 4 & 10 & -17 & 170 & 20 \\
\hline 5 & 15 & -18 & 100 & 22 \\
\hline 6 & 15 & -18 & 110 & 20 \\
\hline 7 & 15 & -18 & 100 & \\
\hline
\end{tabular}

Determination of angels used using calculation:

\begin{tabular}{rccc}
\hline 34 & -34 & 0 \\
\hline & & 20 & \\
\hline-2 & 22 & 0 \\
& 32 & 20 & \\
\hline
\end{tabular}

Figure 5. Salt Angle

$$
\begin{gathered}
\Delta X=\frac{-32+(-34)}{2}=-33 \\
\Delta Y=\frac{-2+0}{2}=-1 \\
\alpha=\operatorname{tg} \frac{\Delta Y}{\Delta X} \\
=\operatorname{tg} \frac{-1}{-33}=1.74
\end{gathered}
$$

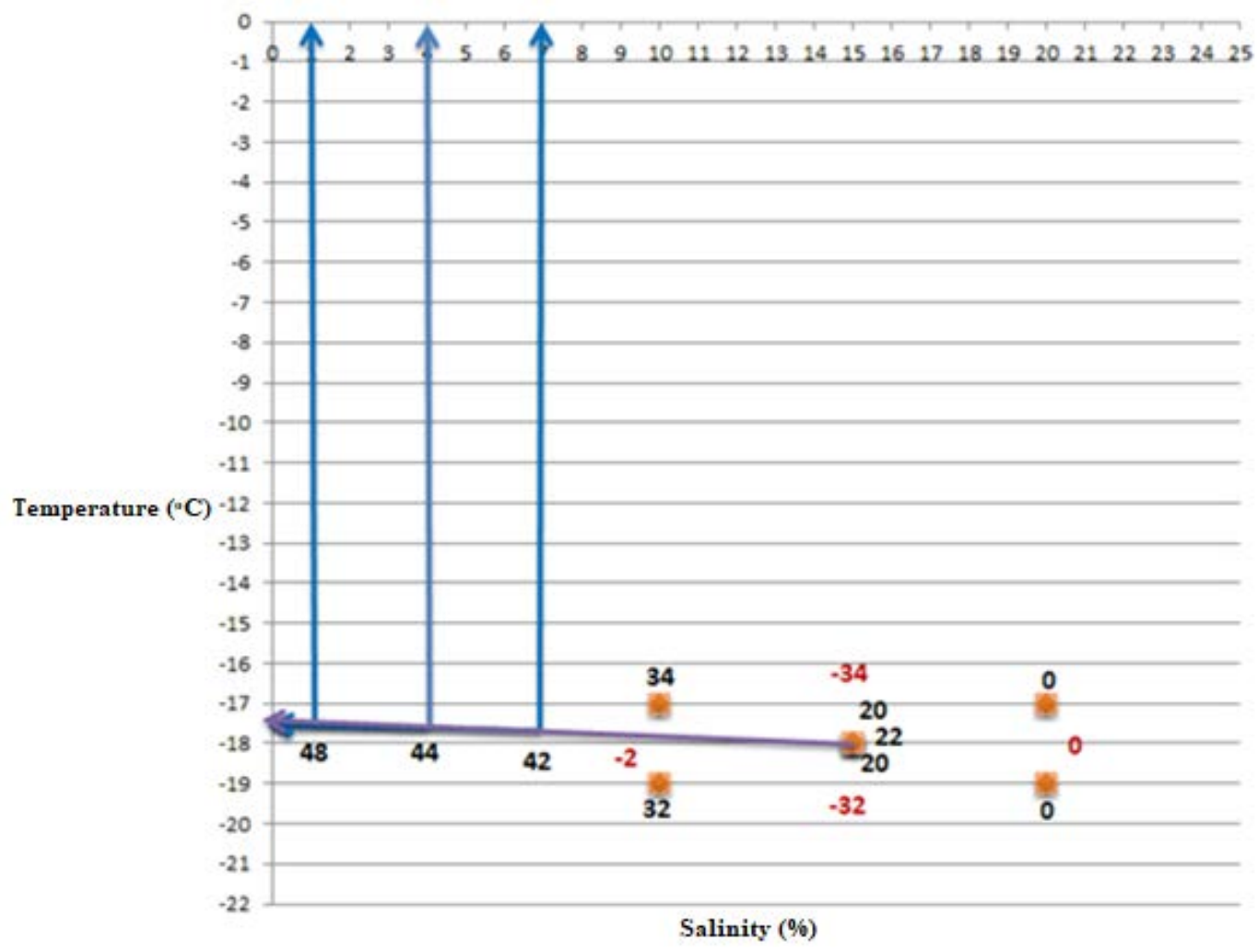

Figure 6. Graph of Experimental Results in Salt 


\section{Conclusions}

In both types of salt cannot carry out RSM experiments for the first order secondary steps. This is caused by the following $[3,4,5]$ :

a. The results show that the value continues to decrease with a maximum freezing rate of $50 \mathrm{~g} /$ hour and constant for Krosok and $48 \mathrm{~g} /$ hour and continues to decrease to $50 \mathrm{~g} /$ hour constant for salt.

b. Change in the percentage of salinity is limited because if the water adds more salt, it will become saturated so that it cannot dissolve completely.

c. The freezer temperature changes are limited according to the specifications of the refrigerator.

On the graph of the Krosok, the freezing rate tends to the bottom left at an angle of $15.25^{\circ}$. On the graph of the salt, the freezing rate tends to the upper left with an angle of $1.74^{\circ}$. This indicates that the salinity is more influential than the temperature of the freezer.

The results obtained for both types of salt are, the lower the salt content, the faster the freezing rate. As for the type of salt, the fastest freezing rate according to the results of the data obtained is salt.

\section{REFERENCES}

[1] Oehlert, Gary W, (2010), “A First Course in Design and Analysis of Experiments”.

[2] P. Beckel, P. Diggle, (1999), "Linear Models Least Square and Alternative”, Second Edition, Springer.

[3] Jabarullah, N.H. (2019) Production of olefins from syngas over $\mathrm{Al} 2 \mathrm{O} 3$ supported $\mathrm{Ni}$ and $\mathrm{Cu}$ nano-catalysts, Petroleum Science and Technology, 37 (4), 382 - 385.

[4] Jabarullah, N.H. \& Othman, R. (2019) Steam reforming of shale gas over $\mathrm{Al} 2 \mathrm{O} 3$ supported $\mathrm{Ni}-\mathrm{Cu}$ nano-catalysts, Petroleum Science and Technology, 37 (4), 386 - 389.

[5] Singh, A. K., \& Issac, J. (2018). Impact of Climatic and Non-climatic Factors on Sustainable Livelihood Security in Gujarat State of India: A Statistical Exploration. Agriculture and Food Sciences Research, 5(1), 30-46.

[6] Abbasov, I. B., \& V'iacheslav, V. O. (2017). Computational Modeling of Multi-Purpose Amphibious Aircraft Be-103. Review of Computer Engineering Research, 4(1), 1-10. 